17. Scheurs PJG, van de Willege G, Tellegen B, et al. Utrechtse Coping Lijst. Lisse: Swets \& Zeitlinger, 1988.

18. van der Ploeg HM, Defares PB, Spielberger CD. The Dutch version of the Spielberger State-Trait Anxiety Inventory, STAI$D Y$. Lisse: Swets \& Zeitlinger, 1980.

19. Wallston KA, Wallston BS, DeVellis RF. Development of the Multidimensional Health Locus of Control Scales. Health Education Monographs 1978; 6: 160-70.
20. Kaptein AA. Psychological correlates of length of hospitalization and rehospitalization in acute severe asthma. Soc Science Med 1982; 16: 725-9.

21. Luteijn F, Starren J, Van Dijk H. Nederlandse Persoonlijkheids Vragenlijst. Lisse: Swets \& Zeitlinger, 1985.

22. Haahtela T, Jarvinen M, Kava T, et al. Comparison of a $B_{2}-$ agonist, terbutaline, with an inhaled corticosteroid, budesonide, in newly detected asthma. N Engl J Med 1994; 331: 700-5.

\title{
A randomised trial of the initiation of asthma treatment
}

\author{
A.H. Morice and M.E. Taylor
}

\begin{abstract}
Objective: To compare the effectiveness of four classes of anti-asthma medication as initial treatment in a randomised open study in an asthma clinic setting.
\end{abstract} Design and subjects: Eighty-six patients aged 16-70 years were recruited into an open trial following informed consent. The diagnosis of asthma was established by either a $15 \%$ diurnal variability in peak expiratory flow (PEF) or a $>15 \%$ bronchodilation to inhaled salbutamol. Patients were randomised to one of the following drug classes: a short-acting $\beta_{2}$-agonist $(n=21)$; an inhaled steroid $(n=25)$; nedocromil sodium $4 \mathrm{mg}$ qds $(n=22)$; and oral theophylline $(n=18)$. Symptoms and daily PEF measurements were recorded on a diary record card. Results: Baseline characteristics of the four groups

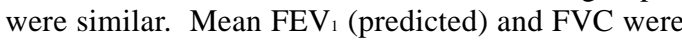
$2.61(82 \%)$ and $3.61(91 \%)$, respectively. Wheeze, cough and expectoration were present on 4.2, 3.8 and 2.8 days per week. At one month, the greatest improvement in number of symptom-free days was seen in the group taking the inhaled steroids. Mean days per week with wheeze fell by $1.3(p<0.05)$, cough by 0.5 (NS) and expectoration by 1.5 $(p<0.05)$. Nedocromil sodium produced a mean decrease in symptom days of $0.8,0.3$ and 0.8 , respectively (NS). Other modalities of treatment produced no significant change in symptoms. Mean improvement in $\mathrm{FEV}_{1}$ was greatest in the steroid group $(11 \% ; p<0.02)$ followed by nedocromil sodium $(9 \% ; p<0.02)$. There was no change with short-acting $\beta_{2}$-agonists or theophylline.

Conclusions: Initiation of treatment with antiinflammatory therapy produces the greatest symptomatic and physiological improvement in mild asthma.

\section{INTRODUCTION}

Therapy for asthma shows wide variation between countries. ${ }^{1}$ In part, this is due to health economics with cheaper medications, such as theophyllines, being widely prescribed in developing countries. Even in countries with sophisticated healthcare, there are considerable differences in prescribing practices for the newly diagnosed person with asthma. ${ }^{2}$
Our increased understanding of the chronic inflammatory nature of asthma has led some authorities to advocate the use of anti-inflammatory drugs in first-line management. ${ }^{3}$ In the UK, despite widespread knowledge and acceptance of guidelines recommending the early use of steroids in adults, $\beta_{2}$-agonist bronchodilator therapy alone is still the most widely used first-line treatment. ${ }^{2}$

The objective of asthma management is to improve the quality of life for patients by abolition of symptoms, improvement of lung function, and reduction of severity and frequency of exacerbations. ${ }^{4}$ As the majority of asthmatics are in the mild-to-moderate category, the first choice of antiasthma medication is important both in terms of achieving these objectives and providing costeffective care. In this study we have examined the short-term response of the commonly prescribed asthma medications in a 'real-life' study conducted in a nurse-run asthma clinic designed to be as similar as possible to that seen in primary healthcare.

\section{METHOD}

The trial was approved by the Local Ethics Committee. Patients with mild-to-moderate asthma were recruited by direct referral from interested general practitioners or from hospital departments. Some patients were seen as self-referrals and were randomised after contact with their GP. Only patients not currently taking anti-asthma therapy were recruited. Previous occasional use of $\beta_{2}-$ agonist bronchodilators did not preclude entry into the study.

The diagnosis of asthma was established by the demonstration of one of the following:

- A $15 \%$ diurnal variability in PEF over one week;

- A > 15\% increase in FEV 1 with salbutamol $200 \mu \mathrm{g}$ from a metered dose inhaler;

- A reproducible fall of $15 \%$ in PEF caused by exposure to a precipitating factor.

Informed consent was obtained on the initial visit. Patients were assessed by computerised questionnaire
Alyn Morice

Head of Academic

Department of Medicine

Marion Taylor

Research Nurse

Academic Department of Medicine, University of Hull, Castle Hill Hospital, Castle Road, Cottingham, Hull HU16 5JQ, UK.

Correspondence to: Professor A.H. Morice

Date received: 02/10/98 Date accepted: 15/02/99

Asthma in Gen Pract 1999; 7(1): 7-9. 
for family history, smoking habits, previous episodes of wheeze and shortness of breath, known allergies including hayfever and eczema, current medication and occupation. Lung function was measured in triplicate (Vitalograph Compact). If, at visit one the $\mathrm{FEV}_{1}$ was $<70 \%$ predicted, the patient was randomised at this time otherwise, randomisation took place at visit two after at least one week of observation. Serial PEF readings and symptoms were recorded at home on a diary record card (DRC). A salbutamol inhaler could be used as required throughout the study and, therefore, all patients were instructed on inhaler technique, which was assessed at each visit.

Patients were randomised following baseline assessment from a computer-generated list designed to provide balanced recruitment to one of four classes of asthma medication. The medication was administered in an open fashion and efficacy was assessed over a one-month period. Where possible, patients were randomised to one of two formulations within each class to ensure applicability of the results as a class effect. The four drug classes were:

- A short-acting $\beta_{2}$-agonist (Aerolin Autohaler $200 \mu \mathrm{g}$ prn or Bricanyl Turbohaler $0.5 \mathrm{mg}$ prn; $n=21$ );

- An inhaled steroid (Becotide $200 \mu \mathrm{g}$ bd or Pulmicort Turbohaler $100 \mu \mathrm{g}$ bd; $n=25$ );

- A cromone (nedocromil sodium $4 \mathrm{mg}$ qds; $n=22$ );

- Oral theophylline (Nuelin $250 \mathrm{mg}$ bd or Theodur $300 \mathrm{mg}$ bd; $n=18$ ).

Once randomised, the patient was required to complete a DRC for one month, recording serial PEF readings, daily symptom scores on a scale of nought to nine, night-time disturbance and daily use of relief

Table 1: Baseline characteristics of patients enrolled into the study

\begin{tabular}{lccll} 
Baseline & \multicolumn{1}{c}{ Steroid } & Cromone & Theophyline & B2-agonist \\
\hline FEV ${ }_{1}(\mathrm{SD})$ \%predicted & $2.8(1.3) 84.7$ & $2.3(1.1) 71.2$ & $2.6(1.2) 73.7$ & $2.5(0.8) 81.9$ \\
FVC (SD) \%predicted & $4.0(1.4) 98.7$ & $3.4(1.2) 90.4$ & $3.7(1.3) 87.9$ & $3.4(1.1) 93.9$ \\
$\begin{array}{l}\text { Days per week with } \\
\text { wheeze (SD) }\end{array}$ & $4.3(3.1)$ & $5.0(2.7)$ & $5.4(2.2)$ & $3.3(3.2)$ \\
$\begin{array}{l}\text { Days per week with } \\
\text { cough (SD) }\end{array}$ & $3.7(3.3)$ & $4.6(3.1)$ & $2.8(3.0)$ & $4.3(3.2)$ \\
$\begin{array}{l}\text { Days per week with } \\
\text { sputum (SD) }\end{array}$ & $3.0(3.2)$ & $4.1(3.3)$ & $1.8(2.3)$ & $2.6(3.2)$
\end{tabular}

Table 2: Lung function and symptom scores following one month of treatment ${ }^{*} p<0.05,{ }^{* *} p<0.02$

\begin{tabular}{lcccc} 
After one month & Steroid & Cromone & Theophyline & B $_{2}$-agonist \\
\hline FEV 1 (SD) & $3.1(1.5)^{\star *}$ & $2.5(1.2)^{\star}$ & $2.6(1.5)$ & $2.5(1.0)$ \\
FVC (SD) & $4.1(1.7)$ & $3.4(1.3)$ & $3.7(1.5)$ & $3.3(1.3)$ \\
$\begin{array}{l}\text { Days per week with } \\
\text { wheeze (SD) }\end{array}$ & $3.0(2.6)^{*}$ & $4.2(3.0)$ & $3.8(2.9)$ & $3.5(3.2)$ \\
$\begin{array}{l}\text { Days per week with } \\
\text { cough (SD) }\end{array}$ & $3.2(3.2)$ & $4.3(3.2)$ & $3.5(3.2)$ & $4.1(3.5)$ \\
$\begin{array}{l}\text { Days per week with } \\
\text { sputum (SD) }\end{array}$ & $1.5(2.0)^{*}$ & $3.3(3.3)$ & $1.9(2.7)$ & $2.4(3.3)$
\end{tabular}

medication. If the patient was randomised to theophylline subsequent visits were arranged to assess theophylline blood levels until therapeutic levels of $10-20 \mathrm{mg} / \mathrm{l}$ were achieved.

In the event of an adverse reaction or worsening of DRC symptoms, patients were instructed to contact the clinic as soon as possible to discontinue the medication and introduce second-line medication.

ANOVA was used to determine the degree of statistical significance of any differences between treatment arms in changes from baseline values following one month's treatment.

\section{RESULTS}

Baseline characteristics of the four groups were similar; mean $\mathrm{FEV}_{1}$ (predicted) was $2.61(82 \%)$; FVC was $3.61(91 \%)$. Wheeze, cough and expectoration were present on 4.2, 3.8 and 2.8 days per week (Table 1).

At one month, the greatest improvement in the number of symptom-free days was seen in the group taking inhaled steroids. Mean days per week with wheeze fell by $1.3(p<0.05)$ cough by 0.5 and expectoration by $1.5(p<0.05)$. Nedocromil sodium produced similar but less striking results $(0.8,0.3$ and 0.8 , respectively; NS). Other modalities of treatment produced no significant change in symptoms (Table 2). In this group of people with mild asthma mean improvement in $\mathrm{FEV}_{1}$ was greatest in the steroid group $(11 \% ; p<0.02)$ followed by the nedocromil sodium $(9 \% ; p<0.02)$. There was no change with short-acting $\beta_{2}$ agonists or theophylline (Table 2).

\section{DISCUSSION}

In this comparison of four commonly prescribed therapies for mild asthmatics, we have confirmed the efficacy of inhaled steroids both in reducing symptoms and improving lung function. A similar, but less marked, improvement was seen with nedocromil sodium. There was no overall improvement with bronchodilator therapy alone.

Our patients were relatively naïve to asthma treatment, having previously only received inhaled bronchodilator medication or no therapy at all. They were thus very similar to many asthmatics seen in the early stages of the disease in primary care. In an attempt to mimic the clinical setting, it was decided to administer the medication in an open-label fashion. Although this prohibits any definite conclusions being drawn as to the absolute efficacy of the medications studied, it does allow for comparisons to be made between treatment groups. Previous studies have demonstrated the bronchodilating effect of inhaled steroids in mild-tomoderate asthma even in subjects whose symptoms are not troublesome. ${ }^{5}$ The striking finding of our study is that inhaled steroids were effective not only in terms of lung function, but also in reducing the number of symptomatic days even after only one month of treatment whereas inhaled bronchodilators had no clinically important effect on symptom frequency. It is questionable as to whether the current recommendation that treatment be initiated 
with bronchodilators is soundly based. Our findings probably reflect the efficacy of inhaled steroids on airway inflammation. Bronchial hyperresponsiveness, a surrogate for airway inflammation, is improved in these patients. ${ }^{5,6}$ In Haahtela's study of the long-term treatment of mild-to-moderate asthma with inhaled steroids or $\beta_{2}$-agonists, ${ }^{5}$ there was almost complete clinical recovery and normalisation of lung function with confirmed use of inhaled steroids.

In the subgroup of treated patients, bronchial biopsy specimens showed significant reductions in the number of inflammatory cells after budesonide treatment. ${ }^{7}$ Those patients who have a poor response to inhaled steroids are usually those with a more prolonged history before commencement of antiinflammatory treatment. ${ }^{8}$ Our study may therefore provide further evidence for the benefit of early intervention with inhaled steroids in asthma.

We found that the cromone nedocromil sodium had a similar spectrum of activity on symptoms and lung function, but was less potent. This is consistent with the known activity of nedocromil sodium being antiinflammatory, but to a lesser degree than that of inhaled steroids. Within the group of patients responding to nedocromil sodium, as might be anticipated, some patients reported considerable benefit. Whether such patients respond as well as they would to inhaled steroids, thereby establishing nedocromil sodium as a true alternative to inhaled steroids in a subset of patients, is unknown. Unfortunately, there appears to be little likelihood of long-term efficacy studies for this group of compounds.

What is the best first-choice treatment for patients with mild-to-moderate asthma? National guidelines suggest the use of $\beta_{2}$-agonists as the first choice, with early intervention with a low-dose inhaled steroid.
The results of our study suggest that those patients taking short-acting $\beta_{2}$-agonists are following a treatment which does not improve lung function and provides poor symptomatic relief. This indicates a need for large-scale studies of first-use inhaled steroids in mild-to-moderate asthma in primary care

\section{Acknowledgements}

We acknowledge the financial support of the following companies: Astra UK, GlaxoWellcome, Fisons and $3 \mathrm{M}$.

\section{References}

1. Janson C, Chinn S, Jarvis D, et al. Physician-diagnosed asthma and drug utilisation in the European Community Respiratory Health Survey. Eur Resp J 1997; 10: 1795-802. 2. Reid J, Orca S, Penrose A, et al. The diagnosis and initial treatment of asthma in young children in New Zealand and the United Kingdom. N Z Med J 1998; 111: 248-51.

3. Barnes PJ. Current issues for establishing inhaled corticosteroids as the anti-inflammatory agents of choice in asthma. J Allergy Clin Immunol 1998; 101: S427-33. 4. The British Thoracic Society, The National Asthma Campaign, The Royal College of Physicians of London, et al. The British Guidelines on Asthma Management. 1995 Review and Position Statement. Thorax 1997; 52(Suppl 1): S1-21. 5. Haahtela T, Jarvinen M, Kava T et al. Comparison of a $\beta_{2}$-agonist, terbutaline, with an inhaled corticosteroid, budesonide, in newly detected asthma. N Engl J Med 1991; 325: 388-92.

6. Juniper EF, Kline PA, Vanzieleghem MA, et al. Effect of long-term treatment with an inhaled corticosteroid (budesonide) on airway hyperresponsiveness and clinical asthma in nonsteroid-dependent asthmatics. Am Rev Respir Dis 1990; 142: 832-6.

7. Laitinen LA, Laitinen A, Haahtela T. A comparative study of the effects of an inhaled corticosteroid, budesonide, and a $B_{2}$ agonist, terbutaline, on airway inflammation in newly diagnosed asthma: a randomized, double-blind, parallel-group controlled trial. J Allergy Clin Immunol 1992; 90: 32-42.

8. Selroos O, Pietinalho AB, Lofroos AB, et al. Effect of early $v s$ late intervention with inhaled corticosteroids in asthma. Chest 1995; 108: 1228-34.

\section{Preschool children with asthma: Do their GPs know?}

M.J.A. Tasche, J.H.J.M. Uijen, B.P. Ponsioen, L.W.A. van Suijlekom-Smit, J.C. de Jongste and J.C. van der Wouden

\begin{abstract}
Objective: To answer the following question: Are children with asthma known to their GP?

Methods: Parents of all 464 children, $1-3$ years of age and registered with five general practices, received a postal questionnaire asking about asthma symptoms of the child, and past and present asthma medication. Thus, children were classified as having no, mild, moderate or severe asthma. The GPs' records were checked for recorded asthma symptoms, medication and asthma-related diagnoses. The presence of these items was compared with asthma severity.
\end{abstract}

Results: Eighty-seven percent of parents responded to the questionnaire (mean age of children 30.1 months). For all classes of severity, $75 \%$ of children with asthma were known to their GP. Although all children with severe asthma were known to their GP, the proportion of asthmatic children known to their GP fell with decreasing severity. Symptoms and medication were recorded more often than asthmarelated diagnoses.

Conclusions: Most preschool children with asthma are known to their GP. The diagnosis is recorded less often than asthma symptoms and medication. 